\title{
A Study on the Eating disorders
}

\section{- Focusing on Eating behavior -}

\section{Background}

- Eating disorders are a pathological states of extreme eating behaviors that ignore the biological desire (Kiriike, 2005) and, they involve eating behavior problems.

- They have been studied from the viewpoint of the parent-child relationship and the desire for thinness (Baba, 2013).

- New findings, however, elucidate the course of eating disorders from the perspective of eating behavior.

- This study aims to clarify the details of eating behavior in eating disorders, considering the detailed process of the change.

\section{Methods}

- Seven women (teenagers to woman in their forties) with a history of diagnosis of eating disorder (anorexia nervosa) participated in this study.

- Participants were confirmed to be in a state of remission.

- First, I provided adequate explanation for research, and then conducted an interview after agreement was obtained.

- All interview contents were transcribed.

- This interview data was analyzed using the grounded- theory approach (Saiki, 2013), which emphasizes the verifiability of data and generates new theory.

Table 1 Participants of Study

\begin{tabular}{|c|c|c|c|}
\hline & age & $\begin{array}{l}\text { History of } \\
\text { diagnosis }\end{array}$ & $\begin{array}{l}\text { Reason for selection of } \\
\text { participants }\end{array}$ \\
\hline A & $20 \mathrm{~s}$ & $\mathrm{AN}(\mathrm{B} / \mathrm{P})$ & $\begin{array}{l}\text { The generation of basic } \\
\text { categories in AN (Binge- } \\
\text { eating/purging type) }\end{array}$ \\
\hline B & $30 \mathrm{~s}$ & $A N(R)$ & $\begin{array}{l}\text { The generation of basic } \\
\text { categories in AN (Restricting } \\
\text { type) }\end{array}$ \\
\hline c & $20 \mathrm{~s}$ & $A N(R)$ & $\begin{array}{l}\text { Repeat hospitalization and } \\
\text { discharges }\end{array}$ \\
\hline D & $10 \mathrm{~s}$ & $A N(R)$ & Fewer years after remission \\
\hline E & $50 \mathrm{~s}$ & $A N(R)$ & More years after remission \\
\hline $\mathbf{F}$ & $50 \mathrm{~s}$ & $\mathrm{AN}(\mathrm{B} / \mathrm{P})$ & Analysis for confirmation \\
\hline G & $20 \mathrm{~s}$ & $\mathrm{AN}(\mathrm{B} / \mathrm{P})$ & Analysis for confirmation \\
\hline
\end{tabular}

AN: Anorexia Nervosa

B/P: Binge-eating/purging type R: Restricting type $※ \mathrm{E}, \mathrm{F}, \mathrm{G}$ are now vegetarians.
Table 213 generated categories Generated categories

\section{Refusal to eat}

Purging behavior and excessive exercise

Decreased food intake

Diet based on calories

Vegetarian diet

General diet

Awareness that eating is fun

A sense of security in a vegetarian diet

Disagreements with vegetarian ideas

10 Awareness that

"I don't gain weight suddenly."

11 A sense of security with a diet based on calories

2 Regretting the period of anorexia

13 Sense of fear about the physical condition

14 Fear of eating behaviors

Onset of eating disorder

16 Lack of insight into disease

\section{Findings}

- The analysis generated 13 categories. Based on these generated categories, the process of change from the state of refusing eating behavior is shown in the model diagram(Figure 1)

- In this model, the time series passes from left to right.

- Eating disorders involved conflicts of a "Fear of eating behavior" and a "Sense of fear against the physical condition ."

- The conflict process was managed by "justifying the reason for eating."

- In the process, it is important to realize that "I don't suddenly gain weight."

- As a result, it gradually became possible to eat various things.

- Depending on the patients, conflict resolutions are different; some participants began general eating behavior while others began eating behavior with avoiding animal food.

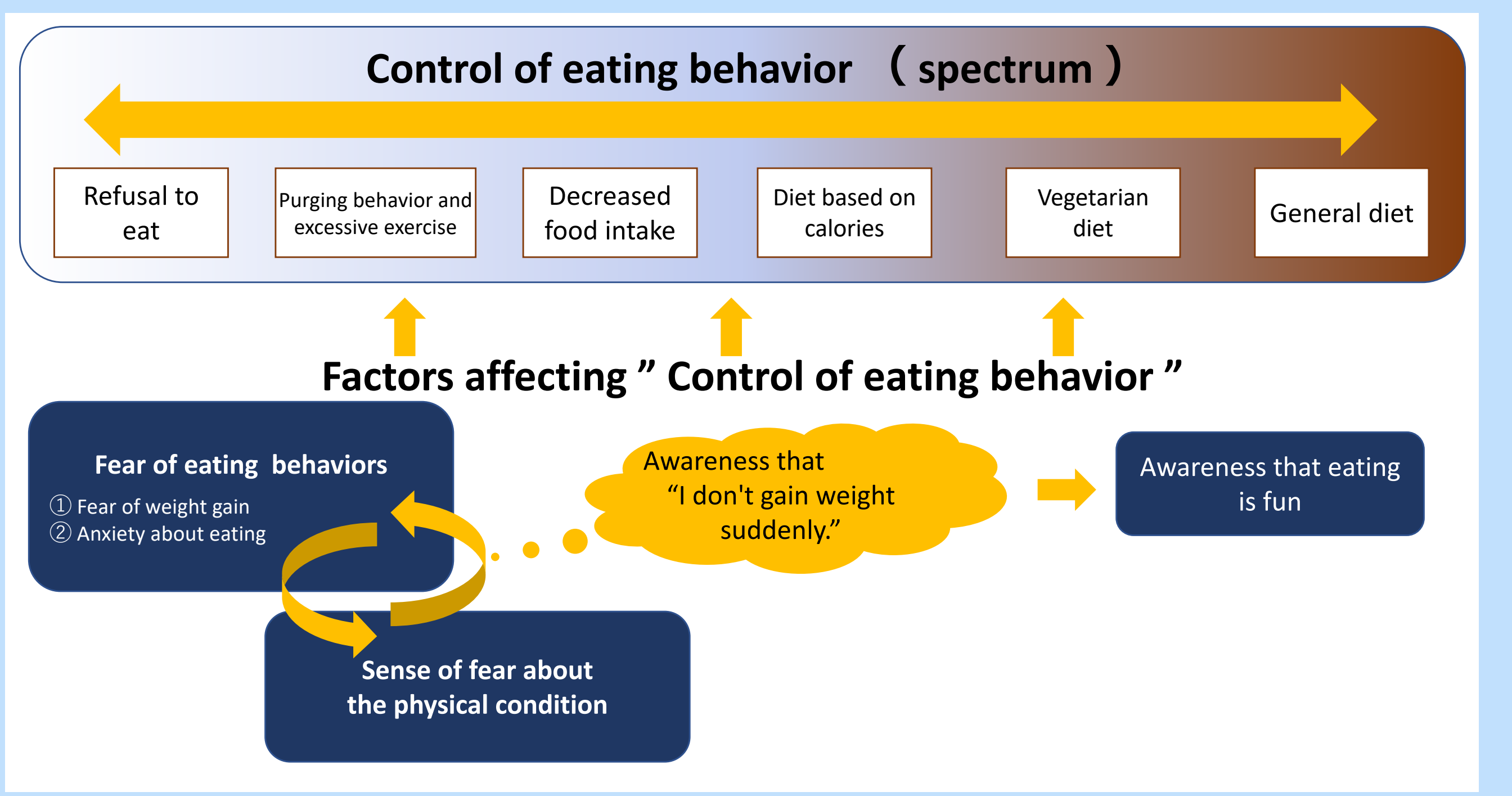

Figure 1 Model of the altered process of eating behavior

\section{Discussion}

- For remission of eating disorders, the process of convincing oneself is important.

- When following that process by "justifying the reason for eating," it gradually becomes possible to eat various foods.

Kiriike,Nobuo(2009). Eating disorders - I do not eat it, I can not eat it, I can not stop eating it- 2nd edition , Igakusyoin, p5(in Japanese) Saiki,Kureiguhiru, Syoko(2013). Qualitative research method Seminar 2nd edition: Learning the grounded theory approach, Igakusyoin, (in Japanese)

Baba,Kenichi(2013). Recent treatments for eating disorders, Chapter1, Kongousyuppann, pp10-25, (in Japanese) 